\title{
Quality Learning Environments: Design-Studio Classroom
}

\author{
Asem Obeidat ${ }^{1} \&$ Raed Al-Share ${ }^{2}$ \\ ${ }^{1}$ Interior Design, Yarmouk University, Irbid Jordan \\ ${ }^{2}$ Faculty of Engineering Technology, Al-Balqa Applied University, Amman Jordan \\ Correspondence: Raed Al-Share, Faculty of Engineering Technology, Al-Balqa Applied University, P.O. Box \\ 15008, Amman 11134, Irbid Jordan. E-mail: raed_shara@yahoo.com
}

Received: February 22, 2012 Accepted: April 12, 2012 Published: July 1, 2012

doi:10.5539/ach.v4n2p165 URL: http://dx.doi.org/10.5539/ach.v4n2p165

\begin{abstract}
Design education requires a specific setting that facilitates teaching/learning activities including lecturing, demonstrating, and practicing. The design-studio is the place of design teaching/learning activities and where students/students and students/instructor interaction occur. Proper interior design improves not only the function of such learning environment but also the confidence of its users involved in the teaching/learning process. This study finds impetus in the lack of research data relative to the design of the design-studio classroom, most crucial space in design and architectural education. The purpose of the study is to examine the design-studio classroom environment and to determine, by the perception of its users, to which level this specific environment assures users' needs and objectives. A survey was developed and distributed to a purposive sample of design and architecture educators. Ninety four responds were collected. The results of the study support the stability of earlier findings that the physical environment has a direct impact on the satisfaction of the space users. The findings suggest that lighting, noise, glare, air quality, temperature, seats comfort and possibilities of arrangement are all essential environmental features in the achievement of an appropriate pedagogic environment. Likewise, it was found that designated workstations are important part of the teaching/learning process of design. It also emerges from this study that lighting is the most important feature.
\end{abstract}

Keywords: design-studio, design education, interior design, learning environment

\section{Introduction and Purpose}

It is becoming more evident that learning environments such as schools and universities are less equipped to fulfill students and instructors pedagogic needs than other environments (Lyons, 2001). More often than not, learning environments are uninteresting and uninviting (Kennedy \& Agron, 2004). Research findings suggest, however, that a high quality interior design improves not only the function of a learning environment but also the confidence of its users involved in the teaching/learning process (Webber, Marini, \& Abraham, 2000).

The interior design of spaces such as offices, dining halls, libraries, auditoriums, and classrooms should satisfy the minimum requirements of making these spaces more functional, healthier, and more enjoyable. Students and instructors suffer from interior problems of classrooms such as inadequate lighting, noise, glare, poor air quality, inappropriate temperature, uncomfortable seats and inflexible seating arrangement (Rydeen, 2003). The classroom is the most important area in a school. It is an environment that includes various aspects such as psychological, cultural, social, and physical. It is where students and teachers spend a large amount of their time and, hence, it is an environment that is assumed to promote a reasonable level of concentration in learning activities such as discussing, reading, drafting, drawing, writing, and practicing. Designers ought to pay enough attention to environmental aspects when designing classroom environments. They should create a human-centered environment that supports teaching/learning processes and enhances students' and instructors' performance (Rydeen, 2003).

Classrooms vary in size and function, depending on what teaching/learning activities are intended. Lecture-based teaching/learning activities, for instance, may require a different setting than other demonstration-based activities. Interior design teaching/learning activities, which may include lecturing, demonstrating, and practicing, require a specific setting that should be designed to facilitate such activities. The design-studio 
classroom is the most crucial space in interior design and architectural education; such space facilitates learning and social activities and influence student's interests and curiosity (Smith, 2011; Demirbas \& Demirkan, 2000). Such learning environment has been described as a place where students carry out their projects while administered by their instructors (Lackney, 1999). Its space could fit up to twenty students interacting with each other; each has his/her own drafting table, tools, and other educational belongings. Demirbas \& Demirkan also pointed out that the design-studio classroom could be (a) a learning environment that facilitates interior design teaching/learning processes during regular class hours; (b) a learning environment that enables interior design students to work on their own project in their spare of time; and (c) a learning environment that could serve both concepts at the same time; students could work on their own projects while others are enjoying a class. Interior design students may spend much of their time in such classroom environments; therefore, these classrooms should facilitate such objectives and provide conditions supportive of these multiple activities.

The purpose of the study is to examine the design-studio classroom environment, and to determine, by the perception of its users, to which level this specific environment assures users' needs and objectives.

\section{Significance of the Study}

As the ultimate purpose of this study is to create a typical design-studio classroom environment that satisfies the users' needs, this study will assist others who are coping with these specific learning environments such as researchers, interior designers, facility managers, policy makers, and architects. Outcomes of the study will contribute to improving such environments in use today, and will provide basic guidelines for designing future ones, as well. This study will also benefit design and architecture educators in their teaching processes; it will enable them to employ various teaching methods and instructions. In addition, design and architecture students will have a better environment for learning, one that would enable both individual and group learning, use various learning resources, and even allow users to enjoy learning times.

\section{Research Questions}

Learning environments vary in size and type depending on the function and type of learning anticipated, including discussion, meeting, training, seminar, workshop, or project work. The design-studio classroom is a learning environment that should support design teaching/learning activities both during and outside of class hours. Such activities may include collaborative learning, problem-solving, lecturing, team-work, and one-on-one teaching activities. Designers need to determine the function and teaching mode of each environment in order to provide a supportive design (Webber et al., 2000).

Specifically, this study attempts to study the importance of the designated design-studio workstation in a typical design studio-classroom setting. This will be achieved through the examination of the physical interior elements (i.e., space layout, color, lighting, hearing, furnishing, and seating arrangement) as pertaining to the workstation and its correlation to the overall composition of the design studio-classroom and its consequences on the pedagogic performance. To do so, the following three research questions will be addressed:

1) How important is to have a designated design-studio workstations in the design programs?

2) What are the factors, both positive and negative, and characteristics of the design-studio classroom environments that are most important for teaching/learning process of design?

3) How do design and architecture educators use the design-studio classroom environment in their teaching procedures?

\section{Literature Review}

The impact of design on human life was examined generally in several previous studies. Evans \& McCoy (1998) indicated that to attain a well designed environment that fits well with human needs, it is important for designers to understand how a physical environment impacts its users. The built environment affects human behavior either negatively or positively (Sommer, 1969; Altman, 1970). As pointed out by Demirbas \&. Denirkan (2000), learning environments are assumed to be more useful for the educational purposes if they are designed to meet user's needs; it is the place where creativity begin. As a consequence, there are several aspects of the classroom environment that may affect teaching-learning activity. One example is the effect of physical surroundings (Webber et al., 2000).

The classroom is a place where the teaching/learning process occurs, where students and instructors spend extended time and formulate social/academic interactions. Such interactions occur within the physical context of interior elements such as furniture, color, light, temperature, and space. In fact, surrounding elements may not merely create a pleasant atmosphere; they also facilitate a particular behavior and affect students' performance 
and satisfaction (Bitner, 1992). According to Clitheroe, Stokols, \& Zmuidzinas (1998); these elements would either be supportive or unsupportive of students'/instructors' performance. For instance, fixed seats may not always enable group discussion if they are fastened to the floor. In contrast, movable seats will be more supportive for interaction in the classroom and, therefore, may increase academic performance (Webber et al., 2000). When the physical surroundings of an environment fulfill the users' needs and support their activities, a synomorphic relationship arises between users and such surroundings (Wicker, 1984). The concept of synomorphy, according to Wicker, represents a "good-fit" between a thing and its container. A well-fit between a physical environment and its users occurs when everyone in such setting is comfortable, as once a classroom environment accomplishes its function by being appropriate both physically and psychologically for the number of students.

Physical and psychological human dimensions are important to bear in mind at this stage in order to address various patterns and needs of the users. In general, when a user is not fully satisfied with a specific environment, physically or psychologically, he/she tends to search for proper conditions (Lang, Burnette, Moleski \& Vachon, 1974). As human beings are socially interconnected, they usually tend to search for elements that are supportive of social interaction. Students need to connect with each other in the classroom, both socially and academically. Therefore, it is important to create supportive space layouts to ensure various interaction patterns among users. For example, supportive space layouts with flexible seating arrangements enable different patterns of interaction, connect people with each other, and facilitate collaboration and team-work (Sommer, 1967; Mehrabian \& Diamod, 1971). Unsupportive layouts, however, decrease such connection and interaction. Spaces that discourage interaction patterns are considered dull, empty, huge, and meaningless (Sommer, 1967). One example of such a notion is a back-to-back seating arrangement which prohibits team-work and collaborative learning in classroom environments (Osmond, 1959; Douglas \& Giffort, 2001). Yet, seating arrangement in design-studio classroom is considered supportive when interaction among students/students and students/instructors is encouraged and collaborative learning is ensured.

Teaching/learning style plays a major role in shaping the classroom space layout. As indicated by Webber et al. (2000), a particular teaching style may require a specific setting. In this case, flexibility in seating arrangement to facilitate teaching methods, learning objectives, and diverse learning abilities will be essential.

Educational institutions ought to consider the importance of learning environments and their impact on the teaching/learning process; they should provide appropriate and supportive physical settings. The way the classroom is designed, according to Herman Miller, Inc., (1994), affects students' inspiration, concentration, behavior, well being, and performance. Well-planned learning environments, in this regard the design-studio classroom, with flexible and comfortable furniture, appropriate lighting and temperature will positively support teaching/learning experience (Douglas \& Robert, 2001; Webber et al., 2000).

Students and instructors spend extended periods of their time in classrooms; in fact interior design students and instructors may spend longer time in the design-studio classroom. Students and instructors should, therefore, feel comfortable and satisfied. Demirbas \& Demirkan (2000) pointed out that living procedure should be assured in such learning environments especially when students use it in their spare time. Design-studio classroom, they add, should serve as a pedagogical means that provides comfort and enjoyment.

\section{Methodology}

A survey was developed and distributed to a purposive sample of design and architecture educators. The survey instrument included 13 questions designed to address the three main research questions. Two of the survey questions provided background information about the participants, while the rest of the questions addressed their perceptions regarding studio classroom environments.

Because this study inquire about the perceptions of design and architecture educators who are actively involved with matters pertinent to the teaching of design in Jordan, the researchers decided to use a convenience purposive sample. The sample consisted of the members of the Design and Architecture Association in Jordan and others interested and professionals in the design field.

The survey was sent to 500 participants and was conducted as an online questionnaire emailed to all members via their e-mail addresses. There were 85 participants who didn't participate in the survey because of undelivered messages. Only 94 out of 415 of the participants responded, 86 of the respondents answered all questions. The responses of the remaining eight members were not considered because they missed some of the critical questions. 
Survey questions were developed carefully to address the main questions of the study. Firstly, to address the importance of the design-studio workstations, part of the survey questions examined its availability and the number of workstations assigned in each program. Secondly, to address characteristics and features of the design-studio environment, participants were asked to rank the interior environmental features based on the importance. In addition, participants were asked to indicate other interior features that influence the process of teaching/learning interior design. Finally, to examine how design educators use the design-studio in their teaching process, they were asked to indicate their preference of communication strategies to deliver design information. In addition, they were asked to indicate their preference over tools to be used in the design-studio, such as hand drafting and computers.

\section{Findings}

Findings of the study indicated that $40.7 \%$ of the design programs in Jordan already have designated studio workstations. While $55.8 \%$ don't have any, $60.5 \%$ of them are planning to make designated workstations available in the future and $30 \%$ of the participants said that they do not have any plan to do so in the future. The majority of the design programs that have designated studio workstations provide workstations for every student in their program, 3 programs provide it only for graduate students, 5 programs provide it for seniors, and 7 programs provide it for both seniors and juniors (see Table 1).

Table 1. Implementing designated studio workstations in interior design programs in Jordan

\begin{tabular}{llcccc}
\hline & Frequency & Percent & Valid Percent & Cumulative Percent \\
\hline Valid & every student in the program & 27 & 31.4 & 31.4 & 31.4 \\
& & 3 & 3.5 & 3.5 & 34.9 \\
& graduate student only & 5 & 5.8 & 5.8 & 40.7 \\
& senior student only & 6 & 7.0 & 7.0 & 47.7 \\
senior and junior & 45 & 52.3 & 52.3 & 100.0 \\
none & 86 & 100.0 & 100.0 & \\
Total & & &
\end{tabular}

Numbers of designated studio workstations in design programs vary; the majority of these programs (30.2\%) indicated that they have more than 6 workstations, $27.9 \%$ provide $1-3$ workstations. Only 5 programs provide 4-6 workstations (see Table 2).

Table 2. The availability of designated studio workstations in interior design programs in Jordan

\begin{tabular}{llcccc}
\hline & & Frequency & Percent & Valid Percent & Cumulative Percent \\
\hline Valid & $1-3$ & 24 & 27.9 & 43.6 & 43.6 \\
& $4-6$ & 5 & 5.8 & 9.1 & 52.7 \\
& more than 6 & 26 & 30.2 & 47.3 & 100.0 \\
& Total & 55 & 64.0 & 100.0 & \\
Missing & System & 31 & 36.0 & & \\
Total & & 86 & 100.0 & & \\
\hline
\end{tabular}

The number of students enrolled in design studio sections also varies; most of the programs (48.8\%) have 16-20 design students enrolled for each section; $26.7 \%$ of design programs have 10-15 students in each section; $16.3 \%$ of programs have 21-25 students in each section, while only 4 programs have large sections, more than 25 students in each (see Table 3).

Table 3. Students' enrollment in interior design programs in Jordan

\begin{tabular}{|c|c|c|c|c|}
\hline & Frequency & Percent & Valid Percent & Cumulative Percent \\
\hline Valid under 10 & 3 & 3.5 & 3.5 & 3.5 \\
\hline
\end{tabular}




$\begin{array}{lcccc}10-15 & 23 & 26.7 & 26.7 & 30.2 \\ 16-20 & 42 & 48.8 & 48.8 & 79.1 \\ 21-25 & 14 & 16.3 & 16.3 & 95.3 \\ \text { more than } 25 & 4 & 4.7 & 4.7 & 100.0 \\ \text { Total } & 86 & 100.0 & 100.0 & \end{array}$

Having a designated design-studio workstation in design programs is very important; the majority of respondents indicated that it is highly desirable to students learning. In addition, $36 \%$ of respondents said it is desirable to have designated workstations in design programs. Only 2 respondents believe that it is merely somewhat desirable (Table 4).

Table 4. The importance of designated studio workstations in the interior design programs in Jordan

\begin{tabular}{cccccc}
\hline & & Frequency & Percent & Valid Percent & Cumulative Percent \\
\hline Valid & highly desirable & 43 & 50.0 & 50.0 & 50.0 \\
& desirable & 31 & 36.0 & 36.0 & 86.0 \\
neutral & 10 & 11.6 & 11.6 & 97.7 \\
& 2 & 2.3 & 2.3 & 100.0 \\
& somewhat undesirable & 100.0 & 100.0 & \\
Total & 86 & &
\end{tabular}

Teaching design may differ from teaching other areas; it may require specific communication strategies, such as "telling" and "demonstrating". Design educators may prefer a specific communication strategy that he/she considers it as a powerful one. This study indicated that only two educators prefer the telling strategy, while seven instructors prefer demonstrating technique. Clearly, the majority of design instructors who participated in this study prefer both strategies; $75.6 \%$ indicated that they use telling and demonstrating in their teaching. $14 \%$ of participants prefer other strategies than telling and demonstrating such as investigating, inquiring, drawing, team-projects, guiding, listening, seeing, and confirmation (see Table 5).

Table 5. Preferences among methods of teaching interior design in interior design programs in Jordan

\begin{tabular}{cccccc}
\hline & & Frequency & Percent & Valid Percent & Cumulative Percent \\
\hline Valid & telling & 2 & 2.3 & 2.3 & 2.3 \\
& demonstrating & 7 & 8.1 & 8.1 & 10.5 \\
& both telling and demonstrating & 65 & 75.6 & 75.6 & 86.0 \\
& 9 & 12 & 14.0 & 14.0 & 100.0 \\
& Total & 86 & 100.0 & 100.0 & \\
\hline
\end{tabular}

Interior environmental features vary in promoting design teaching/learning activities; they either promote or inhibit teaching/learning process. The participants were asked to rank the importance of specific interior environmental features (furniture, flexibility of furniture arrangement, color, lighting, and temperature) in the design-studio classroom. Responses indicated that lighting is the most important interior feature of the design-studio environment; $30.2 \%$ of the respondents have selected it as "very important". Furniture and flexibility of furniture arrangement were ranked in the level after lighting. $24.4 \%$ of respondents selected those two features as the most important. Temperature was selected as "very important" by $16.3 \%$ of the participants, while only $7 \%$ of the respondents selected the color feature as a very important feature. Lighting in design-studio classroom was the most important feature among other participants of this study. Findings of the study show that $36 \%$ of the respondents selected lighting as very important one (see Tables 6 ).

Table 6.The importance of lighting in design-studio classroom 


\begin{tabular}{cccccc}
\hline & Frequency & Percent & Valid Percent & Cumulative Percent \\
\hline \multirow{2}{*}{ Valid } & Highly Desirable & 26 & 30.2 & 30.2 & 30.2 \\
& Desirable & 31 & 36.0 & 36.0 & 66.3 \\
& Neutral & 17 & 19.8 & 19.8 & 86.0 \\
& Somewhat desirable & 7 & 8.1 & 8.1 & 94.2 \\
& Undesirable & 5 & 5.8 & 5.8 & 100.0 \\
Total & 86 & 100.0 & 100.0 & \\
\hline
\end{tabular}

Furniture was in the second place; $33.7 \%$ said that it is very important. Flexibility was in the third place since $20.9 \%$ respondents selected it. $14 \%$ of the respondents was ranked temperature as very important. Color was the less to be selected as very important; only 2.3 believe it is a very important feature of the design-studio classroom.

Ranking such features as "unimportant" was as follows: color was believed to be the unimportant feature of the design-studio classroom; $59.3 \%$ of the respondents indicated that. $11.6 \%$ are equally ranked both arrangement flexibility and temperature in the second place. While $5.8 \%$ ranked lighting to be in the third place, only $2.3 \%$ of the respondents believed that furniture is unimportant feature.

The most ranked feature as "somewhat important" one was temperature; selected by $32.6 \%$ of the participants. $24.4 \%$ believed that color is fairly important, while flexibility was in the third place. Finally, furniture and lighting were believed to be somewhat important by $10.5 \%$ and $8.1 \%$ of the participants. Tables $7,8,9$, and 10 illustrate the importance of furniture, arrangement flexibility, temperature, and color in design-studio classroom environment.

Table 7. The importance of furniture in design-studio classroom

\begin{tabular}{cccccc}
\hline & & Frequency & Percent & Valid Percent & Cumulative Percent \\
\hline Valid & Highly Desirable & 21 & 24.4 & 24.4 & 24.4 \\
& Desirable & 29 & 33.7 & 33.7 & 58.1 \\
& Neutral & 25 & 29.1 & 29.1 & 87.2 \\
& Somewhat desirable & 9 & 10.5 & 10.5 & 97.7 \\
& Undesirable & 2 & 2.3 & 2.3 & 100.0 \\
& Total & 86 & 100.0 & 100.0 & \\
\hline
\end{tabular}

Table 8. The importance of arrangement flexibility in design-studio classroom

\begin{tabular}{cccccc}
\hline & & Frequency & Percent & Valid Percent & Cumulative Percent \\
\hline Valid & Highly Desirable & 21 & 24.4 & 24.4 & 24.4 \\
& Desirable & 18 & 20.9 & 20.9 & 45.3 \\
& Neutral & 19 & 22.1 & 22.1 & 67.4 \\
& Somewhat desirable & 18 & 20.9 & 20.9 & 88.4 \\
Undesirable & 10 & 11.6 & 11.6 & 100.0 \\
Total & 86 & 100.0 & 100.0 & \\
\hline
\end{tabular}

Table 9. The importance of temperature in design-studio classroom

\begin{tabular}{cccccc}
\hline & & Frequency & Percent & Valid Percent & Cumulative Percent \\
\hline Valid & Highly Desirable & 14 & 16.3 & 16.3 & 16.3 \\
& Desirable & 12 & 14.0 & 14.0 & 30.2 \\
& Neutral & 22 & 25.6 & 25.6 & 55.8 \\
\hline
\end{tabular}




\begin{tabular}{ccccc} 
Somewhat desirable & 28 & 32.6 & 32.6 & 88.4 \\
Undesirable & 10 & 11.6 & 11.6 & 100.0 \\
Total & 86 & 100.0 & 100.0 & \\
\hline
\end{tabular}

Table 10. The importance of color in design-studio classroom

\begin{tabular}{cccccc}
\hline & & Frequency & Percent & Valid Percent & Cumulative Percent \\
\hline Valid & Highly Desirable & 6 & 7.0 & 7.0 & 7.0 \\
& Desirable & 2 & 2.3 & 2.3 & 9.3 \\
Neutral & 6 & 7.0 & 7.0 & 16.3 \\
& Somewhat desirable & 21 & 24.4 & 24.4 & 40.7 \\
& Undesirable & 51 & 59.3 & 59.3 & 100.0 \\
Total & 86 & 100.0 & 100.0 & \\
\hline
\end{tabular}

Participants were asked to supply other critical features they valued to promote design teaching/learning process. As stated by respondents, these features included integration of digital technology (e.g., computers and relevant software, printers, TV/V, projection, wireless internet communication), audio-visual equipment, good access to workstations, good acoustics and acoustical privacy, smart-boards, whiteboards and display boards, display areas and stimulating art and design works, ample spaces, access to resource library and interior finish materials, connection to other studios like architecture and art, ergonomic seating, personalization of space, music, safety, privacy, water fountains, couches, natural light, storage space for each station, and enabling teamwork and hands-on-activities.

Respondents were also asked to supply features they thought detracting from the environment indicated features that inhibit design teaching/learning process. These are: improper equipment, shortage of workstations, improper room shape and inadequate workspace, lack of storage spaces, layout of workstations which inhibits attention to instructors, bad acoustics, inadequate ambient conditions such as lighting and temperature, lack of control over environmental elements as temperature and light, lack of natural light and nature view, lack of internet access, lack of computers, plotters and printers, lack of proper technology, non-functioning furniture and inflexibility of furniture arrangement, workstations inadequate size, poor sightlines, lack of circulation hierarchy, computer monitors interfering with viewing, noise, high panels, glare, inadequate HVAC, lack of proximity to resource library/samples, lack of privacy, lack of acoustical privacy, lack of space to sit side-by-side with students, lack of space for informal discussion, lack of visual aesthetics, lack of places to keep personal effects, lack of ownership of the environment, unsuitable workstation for both hand drafting and computer, access to space after class hours, and inaccessibility to workstations.

For better teaching/learning outcomes, the design-studio classroom should be designed carefully; an ideal environment that is to be used by design students may include hand drafting and/or computer capabilities and others, as well. This study indicated that $86 \%$ of the respondents believe that the ideal design-studio classroom should enable both drafting and computer capabilities.

Only one respondent preferred hand drafting capability solely. $11.6 \%$ of the respondents indicated that Workstations should facilitate all modes of design communication such as model building/cutting area, assembling material samples, reading, accessing references, drawing, and CAD.

\section{Discussion}

The aim of this study was to examine the configuration of the design-studio classroom environment in Jordan in order to design a typical one that is more effective. The researchers believe that findings of the study provide reasonable answers to the main research questions.

(1) How important is to have a designated design-studio workstations in design programs in Jordan?

Regarding the importance of designated design workstations, saliently the designated design workstations are very important to design programs in Jordan. Findings of the study indicated that almost $50 \%$ of the design programs already have designated work stations for their students and they will continue to have it in the future. Also, $60 \%$ of programs currently not providing such workstations are planning to provide them for their students. This study considers that designated workstations are important part of the teaching/learning process of 
interior design. In addition, findings of the study suggest that designated workstations should be provided for all students in all levels; such workstations were believed to be supportive of teaching/learning design.

(2) What are the characteristics and factors of the design-studio classroom environments that are most important for teaching/learning process of design in Jordan?

This study suggests that all interior environmental features assumed by the researchers to influence teaching/learning process, are important to be considered in design-studio classroom. Each feature has different level of impact. It emerges from this study that lighting is the most important feature. It may be true that because the process of learning design dealing with lines, shapes, and colors, require proper lighting. It is assumed by this study that a design-studio classroom requires specific furniture such as drafting table and stools. And thus, such furniture should be useful and comfortable, as well. Drafting tables may accommodate storage spaces and proper space for a computer. Stools also need to be comfortable, adjustable, and movable. Flexibility of arranging furniture in design-studio classroom is essential; student may need to rearrange their tables in different ways to facilitate both self-study and team-project, and assist other levels of interaction as well. Based on the findings of the study, furniture and flexibility of arranging furniture are very important features of the design-studio classroom; it support teaching/learning process. Color of the design-studio classroom is not an important issue based on the findings of this study.

(3) How do design educators use the design-studio classroom environment in their teaching procedures?

Regarding the configuration of design-studio classroom environment, this study suggests that such environment should facilitate various teaching methods. The findings indicate that design educators use both telling and demonstrating teaching methods. This may be true because, in order to learn design process, students need to be taught both basic theory and application foundations and to apply such basics by sketching and so forth. Educators use traditional lecturing to deliver theoretical information and one-to-one teaching to guide students through these processes. In order to accomplish such teaching objectives, the study suggests that design-studio classroom should support different teaching methods and enable various patterns of interaction.

\section{Implications}

The purpose of the study was to examine the design-studio classroom environment, particularly designated workstations, its importance, its characteristics, its effect on teaching/learning, and its usage among design educators. Workstations should be assigned for all students in design programs and should facilitate learning, not only during class hours, but also in students' spare time as well. Findings suggest that such workstations are very important for the process of teaching/learning design; students will have a suitable place to work on their own projects, while they may not find an alike in their homes. These workstations should be designed carefully in order to be useful and effective for the users, hence, designers need to pay enough attention to what should be incorporated with it for a more supportive learning environment. There should be specific furniture such as drafting tables and stools.

Drafting tables should be proper to have room for computers and computer screens. Furthermore, drafting tables, stools, and storages should be flexible to rearrange. They should be movable, adjustable, and comfortable. In addition, design-studio workstations should accommodate enough storage spaces and pleasant to make it more functional and enjoyable. In addition, as indicated by participants, the design-studio classroom should enable technology tools such as the internet and data show. It should also accommodate other facilities such as TV/VDT, printers and plotters, display areas, resource library, and access to interior finish materials.

Designers, facility managers, and policy makers of such learning environments, should consider interior environmental features that affect design teaching/learning process. Proper lighting sources, for instance, will make such environment more effective. As findings of this study suggest lighting is the most important aspect of the design-studio classroom, designers should consider both quantity and quality of lighting source to be used, in addition to its locations in the interior space.

Also, another interior environmental feature is temperature. It should be considered cautiously when designing classroom environments. This study shows that temperature could affect design teaching/learning process, therefore, design-studio classroom should accommodate both heating and cooling systems. Besides, control over temperature in such environments is essential.

\section{Limitations of the Study}

Findings will direct researchers' attention to formulate a superior inquiry regarding the design-studio classroom environment. Therefore, a purposeful sample of design educators was thought to be proper at this stage. Findings of this study may not be generalizable enough to all educators of design programs in Jordan. In addition, 
important information could be obtained from larger group of educators and from students, designers, facility managers, and policy makers, as well.

Online survey is a very effective method nowadays; distributing the survey is faster and data analysis is more accurate. For uncontrollable reasons, some surveys did not reach selected participants and others could not open it. Participants who answered all questions were only 86; therefore, the researchers believe that more respondents would be more effective and more generalizable for the body of design educators.

\section{Conclusion}

The impact of physical learning environment is a very important issue; need to be considered cautiously at the beginning stage of the designing process. Not only interior designers, but also educators, facility managers, and stake holders should pay enough attention to what contribute to make such environment more effective and useful. Users of the learning environment should be involved in the designing process; those who are intended to occupy them and whether to suffer or have the benefit of them.

Design-studio classroom environment is a sole environment; designed to facilitate design and architectural education; it is the most usable environment in such disciplines. Design educators and students spend much of their time in the design-studio; both theoretical and practical teaching/learning processes are accommodated in such an environment. Previous studies, (Demirbas \& Demirkan, 2000), indicated the importance of having designated design-studio workstations. Findings of this study verify that such workstations are very important to be offered for all levels of design students. Consistent with previous studies (sommer, 1967; Webber et al., 2000; Webber et al., 2000; Douglas \& Robert, 2001) on physical classroom environments, findings of this study support that physical environmental features have direct impacts on students and educators satisfaction, hence, they should be considered carefully. Lighting and temperature are very important features of the design-studio classroom interior environment that should take precedence in the design process. Interior features of the design-studio classroom should be carefully handled. Furniture should be suitable, movable, adjustable, and flexible. Storage spaces should be enough and reachable by all design students.

Not only traditional hand drafting methods are implemented in the design-studio classroom; but also the computer usage is increasingly becoming a common tool. Consequently, an effective environment should be created carefully to facilitate teaching/learning process and to support its users' performance as well. The design-studio classroom should be functional, comfortable, and enjoyable. This study corroborates Demirbas \& Demirkan (2000) in their description of the design-studio classroom that should support various teaching/learning methods and pleasant working conditions need to be provided.

\section{References}

Altman, I. (1970). Territorial behavior in humans: an analysis of the concept. In L. Pastalan \& D. Carson (Eds.), Spatial Behavior of Older People (pp. 1-24). Michigan: The University of Michigan-Wayne State University.

Bitner, M. J. (1992). Servicecapes: the impact of physical surroundings on customers and employees. Journal of Marketing, 59, 57-71.

Clitheroe, H. C., Stokols, D., \& Zmuidzinas, M. (1998). Conceptualizing the context of environment and behavior. Journal of Environmental Psychology, 18, 103-112.

Demirbas, O. O., \& Demirkan, H. (2000). Privacy dimensions: a case study in the interior architecture design studio. Journal of Environmental Psychology, 20, 53-64.

Douglas, D., \& Gifford, R. (2001). Evaluation of the physical classroom by students and professors: a lens model approach. Educational Research Journal, 43(3), 295-309.

Evans, G. W., \& McCoy, J. M. (1998). When building don't work: the role of architecture in human health. Journal of Environmental Psychology, 18, 85-94.

Hall, E. (1969). The hidden dimension. New York: Doubleday Co.

Herman Miller, Inc. (staff) (1994). A research summary from Herman Miller, Inc. environments for learning. Michigan: Herman Miller, Inc.

Kennedy, M., \& Agron, J. (2004). No buildings left behinds. American School and University.

Lackney, J. A. (1999). A history of the studio-based learning model. Educational Design Institute, Mississippi State University. Retrieved from http://www.edi.msstate.edu/articlesStudio.html 
Lang, J. T., Burnette, C., Moleski, W., \& Vachon, D. (Eds.) (1974). Designing for human behavior: architecture and behavioral sciences. Stroudsburg, PA: Dowden, Hutchinson \& Ross, Inc.

Lyons, J. B. (2001). Do school facilities really impact a child's education? An introduction to the issues. The University of Georgia. Retrieved from http://www.coe.uga.edu/sdpl/sdplcontents/learning\%20environments.html

Mehrabian, A., \& Diamond, S. G. (1971). Seating arrangement and conversation. The American Journal of Sociology, 34(2), 281-289.

Osmond, H. (1959). The relationship between architect and psychiatrist. In C. Goshen (Eds.), Psychiatric Architecture. Washington: American Psychiatric Association.

Rydeen, J. E. (2003). Focusing on Human Factors. American School \& University. Retrieved from http://asumag.com/mag/university_focusing_human_factors/

Smith, K. (2011). Curiositas and studiositas: Investigating student curiosity and the design studio. International Journal of Art \& Design Education, 30, 161-175.

Sommer, R. (1967). Sosiofugal space. The American Journal of Sociology, 72(6), 654-660.

Sommer, R. (1969). Personal space. Englewwod Ciffs, New Jersey: Prentice-Hall.

Webber, L., Marini, M., \& Abraham, J. (2000). Higher education classrooms fail to meet needs of faculty and students. Journal of Interior Design, 26(1), 16-34.

Wicker, A. W. (1984). An introduction to ecological psychology. Cambridge: Cambridge University Press. 